\title{
Mulas, TAMBos y Plata: los Nuevos MATERIAlismos EN los ANDES COLONIALES
}

\author{
Noa Corcoran-Tadd a
}

\begin{abstract}
Resumen
Discusiones recientes acerca un renovado abordaje materialista (frecuentemente denominado los nuevos materialismos), han fomentado una revisita a ciertos principios básicos - ontológicos, epistemológicos, éticos - de las ciencias sociales. Los desafios y posibilidades planteados en estas discusiones entre historiadores, arqueólogos, geógrafos y ecólogos politicos tienen la potencialidad de abrir nuevas perspectivas sobre la naturaleza y la ética de la práctica de investigación, la representación y los objetos de nuestros estudios. Este artículo tiene la forma de una intervención experimental, resaltando las intersecciones múltiples entre las discusiones recientes en la ecología politica neo-materialista y los abordajes arqueológicos sobre la práctica y la representación. Un caso de estudio que explora la arqueología histórica de los Andes coloniales, proporciona un examen breve pero concreto sobre algunos de los potenciales impactos de una aproximación neo-materialista, subrayando nuevos focos sobre el trabajo, la historia animal y la «lentitud» de la práctica arqueológica.
\end{abstract}

Palabras clave: nuevos materialismos, arqueología histórica, praxis arqueológica, Andes coloniales

Abstract

\section{MULES, TAMBOS, AND SILVER: NEW MATERIALISMS IN THE COLONIAL ANDES}

Recent discussions of a renewed materialist approach (often referred to as the new materialisms) have fostered a revisiting of some of the foundational tenets - ontological, epistemological, ethical - of the social sciences. The challenges and possibilities raised in these discussions between historians, archaeologists, geographers, and political ecologists have the potential to open new perspectives on the nature and ethics of research practice, representation, and the objects of our study. This article takes the form of an experimental intervention, highlighting the multiple intersections between recent discussions in new materialist political ecology and archaeological approaches to practice and representation. A case study exploring the historical archaeology of the colonial Andes provides a brief yet concrete examination of some of the potential impacts of a new materialist approach, highlighting new foci on labor, animal history, and the 'slowness' of archaeological practice.

Keywords: new materialisms, historical archaeology, archaeological praxis, colonial Andes

${ }^{a}$ Department of World Archaeology, Faculty of Archaeology, Leiden University (NL)

Correo electrónico: n.e.corcoran-tadd@arch.leidenuniv.nl 


\section{Introducción}

Desde hace mucho tiempo, la ecología política ha sido un ámbito para intersecciones fructíferas entre un enfoque tradicional sobre el ambiente y las nuevas perspectivas materialistas sobre la economía política, el género y los derechos indígenas (Paulson et al. 2003). En los últimos ańos, un grupo de estudiosos, que incluye a Diana Coole, Jane Bennett y Bruce Braun, han buscado destacar y reinterrogar la posición de lo material y la tradición materialista en las discusiones actuales sobre naturaleza, biopolítica y dominio de lo político. En el proceso, han planteado nuevas preguntas sobre los objetos de estudio, los modos de análisis y suposiciones teóricas subyacentes que conforman la práctica de la ecología política.

En tanto disciplina que examina la historia humana a través de sus interrelaciones con el mundo material, la arqueología constituye una posición disciplinaria particularmente interesante para considerar estas nuevas discusiones sobre las fronteras ecológicas entre lo humano y lo no-humano conceptualizadas por varias autores como la «socionaturaleza» (Swyngedouw 1999), los «naturecultures» (Haraway 2003) o la «segunda naturaleza» (Cronon 1991). Hasta ahora, el paso hacia «nuevos materialismos» en la arqueología y la antropología ha tenido una recepción diversa, entre el reconocimiento entusiasta y el escepticismo. Unos arqueólogos lo han recibido como un desarrollo reciente en un giro ontológico más amplio, que busca ir más allá de los debates de los ańos noventa sobre epistemología, a interrogar conceptos fundamentales acerca de la materialidad, la temporalidad y la personalidad (Marshall y Alberti 2014; Witmore 2014).

Pero existe también la perspectiva de quienes proponen que este giro simplemente representa un refrito de antiguos materialismos, una serie de manifiestos sin un programa claro para investigaciones concretas, o la ingeniosa reformulación en última instancia de un idealismo que nos lleva de nuevo a posiciones fuertemente socioconstructivistas (Graeber 2015). Dado el impacto duradero de los «antiguos» materialismos en el pensamiento arqueológico (v.g. Trigger 2006), ¿qué diferencia harían los nuevos materialismos?

De manera importante, estos «materialismos renovados» (Coole y Frost 2010) engranan y aproximan varios debates teóricos en la arqueología, la antropología y disciplinas afines. Mientras las percepciones y limitaciones del giro constructivista se consolidaron durante las últimas dos décadas, los arqueólogos estuvieron cada vez más atraídos al problema de lo material a través de discusiones sobre la materialidad, la teoría del actor-red, la antrozoología, la ética posthumanista y las ontologías relacionales, entre otros aspectos (v.g. Olsen 2003; Knappett 2005; Webmoor 2007; Hodder 2012; Overton y Hamilakis 2013). Muchos de estos préstamos teóricos comparten un materialismo crítico e histórico (frecuentemente basado en las tradiciones marxistas), pero también incluyen posibilidades de un análisis heterodoxo, no-antropocéntrico y atento a nuevas perspectivas relacionales. En este sentido, los nuevos materialismos proporcionan un medio útil para contextualizar estas discusiones teóricas heterogéneas como parte de un cambio más amplio en las ciencias sociales que reconoce los límites del constructivismo y que examina los varios modos en que el mundo de materiales «actúa» $\mathrm{y}$ «resiste» con y fuera de los dominios de lo social y lo humano.

Al mismo tiempo, estas discusiones no pueden subsumirse bajo una posición singular y dogmática; como varios autores se han esforzado en señalar, los nuevos materialismos conforman una orientación más que una serie de proposiciones rígidamente prescritas. Aunque la superposición de intereses y el préstamo de conceptos dan forma a una genealogía intelectual cada vez más complicada, provisoriamente se puede trazar una diversidad en las ciencias sociales, que incluye a los «neoanimistas», que recurren a ontologías no occidentales (v.g. Marshall y Alberti 2014; Watts 2013 influidas por Descola; Viveiros de Castro y de la Cadena), los «demócratas radicales», que cuestionan la composición de lo político (Bennett 2009; Stengers 2010) y los «economistas y ecólogos políticos», que exploran las desigualdades socionaturales (Barad 2007; Braun y Whatmore 2010; Coole y Frost 2010). 
Un compromiso con los nuevos materialismos podría resultar particularmente útil como una nueva lengua franca para cruzar las divisiones tradicionales con otras disciplinas igualmente interesadas en estos abordajes más «lentos» sobre el mundo socionatural ( $c f$. Cunningham y MacEachern 2016 sobre la arqueología como una ciencia «lenta»). Reuniendo una serie de objetos de estudio compartidos y orientaciones metodológicas, arqueólogos, antropólogos, geógrafos y otros, pueden potencialmente generar nuevas discusiones sobre cómo y por qué las cosas llegan a importar (en el sentido tanto físico como ético).

Al explorar una de estas varias tendencias — la ecología política en este caso- algunas de las particularidades de los nuevos materialismos y de la arqueología pueden ser reconsideradas. ¿Hasta qué punto concuerdan las prácticas arqueológicas (aunque no siempre explícitamente), con la orientación neomaterialista emergente? ¿Qué está en juego en una ecología neomaterialista como proyecto ético/político y cómo puede contribuir la arqueología a repensar las divisiones entre quien importa y quien no importa («la partición de lo sensible» adoptado por Bennett 2009), tanto en el pasado como en el presente? ¿Y qué preguntas plantea el encuentro de la arqueología y los nuevos materialismos acerca de las estrategias representacionales y sus límites? La siguiente discusión toma la forma de una intervención de modo experimental y exploratorio, buscando nuevas conexiones entre la arqueología y el dialogo teórico neomaterialista más amplio. Concluyo con un estudio de caso que lleva las preguntas que surgen de este encuentro a la arqueología de la movilidad en los Andes coloniales, explorando las posibilidades y los retos que ofrece una perspectiva neomaterialista.

\section{Prácticas arqueológicas}

Puede parecer aberrante comenzar con la pregunta ¿ya tienen los arqueólogos una perspectiva neomaterialista? Sin embargo, las intervenciones de Tim Ingold (2000, 2007), Carl Knappett (2005), Timothy Webmoor y Chris Witmore (2008) proporcionan tres ejemplos claves de exploraciones teóricas en la arqueología, que reflejan y prosiguen algunas de las más recientes discusiones neomaterialistas en la geografía y la ecología política. Se ha sugerido que los arqueólogos prestamos más atención a los materiales en acción, en lugar de a una materialidad homogénea (Ingold 2007), siempre atentos al peligro del uso simultáneo de «lo social» como una explicación, y a la vez el fenómeno explicado (Webmoor y Witmore 2008). Para esta discusión es importante reconsiderar la posición y constitución del agente humano en el pasado (Knappett 2005) representan importantes precedentes.

Más allá del tumulto del discurso teórico reciente, vale la pena considerar seriamente si la práctica arqueológica existente también puede anticiparse a los intereses de los nuevos materialismos. Uno de los aspectos llamativos de las discusiones neomaterialistas ha sido repensar sus genealogías disciplinarias, con referencia especial a los pensadores que «perdieron» en la evolución del pensamiento hegemónico. Repasando nuestra propia genealogía, es importante considerar que, como arqueólogos, estamos quizás más cerca que otras disciplinas del desarrollo de unas perspectivas neomaterialistas. Mientras que nuestra posición con respecto a la antropología y la invocación frecuente de un lenguaje antropocéntrico podrían sugerir lo contrario, tal vez la arqueología sea (o puede ser) una disciplina «lenta», una práctica de trabajar con las cosas en la cual es más fácil ver en acción el trabajo de trazar, conectar y clasificar los materiales que frecuentemente se queden entre «lo natural»y «lo social».

La brecha persistente entre lo arqueológico y lo etnográfico (Lucas 2012) es clave. A pesar de la antigua tradición norteamericana de ver el foco de las investigaciones arqueológicas como el sistema sociocultural detrás del humano, detrás del artefacto (siguiendo a Flannery 1967), el trabajo del arqueólogo con los conjuntos materiales no se reduce fácilmente a inferencias acerca de lo humano, lo social y/o lo discursivo. De hecho, mucho del trabajo en arqueología actualmente se desarrolla en subdisciplinas (bioarqueología, zooarqueología, geoarqueología, etc.), que forman un halo a los bordes de lo que se puede considerar lo social y lo humano. 
Tan productivas como fueron las discusiones de los años noventa sobre el registro arqueológico como un texto ( $v . g$. Tilley 1991), algunos participantes concluyeron en el reconocimiento de los importantes excesos materiales de este registro, que se extendían más allá de las analogías de lectura del texto (Hodder 2003). El régimen de inscripción-signo-interpretación, basado en las antiguas afiliaciones disciplinarias de la arqueología, ha sido productivo, aunque, en última instancia, insuficiente para capturar los modos a través de los cuales la práctica arqueológica aborda los conjuntos materiales.

Tanto los sistemas como las visiones textuales fueron confrontados con una práctica arqueológica que frecuentemente trabajaba «lentamente» con conjuntos fragmentados de cosas. A pesar de que, en su extremo, esa lentitud puede tener aires románticos al recuperar un sentido de inmediatez perdida (v.g. Ingold 2007), en la mayoría de los casos puede ser caracterizada como una «intimidad analítica» cultivada con el manejo a largo plazo de conjuntos, materiales y objetos ( $c f$. Roberts 2013 sobre la practica de deceleración en la historia de arte).

Más allá de este argumento para una práctica arqueológica que ya está bastante atenta a lo no humano, empero, las preguntas sobre la representación y el posicionamiento disciplinario quedan abiertas. Como han sostenido Bennett y otros, uno de los retos principales planteados por los nuevos materialismos es la posibilidad de una posición no antropocéntrica. Para algunos autores, constituye una necesidad analítica para confrontar los nuevos enredos tecnológicos que están surgiendo entre dominios previamente delimitados como lo humano y lo no humano (Bennett 2009; cf. Braun y Whatmore 2010, xvii para una perspectiva más arqueológica sobre una «tecnicidad originaria» que extiende hacia la prehistoria profunda). Más allá de esto, la posición poshumanista es también una postura ética que busca una nueva "humildad», que vacila en centrar una sola especie y que pone en duda la postura modernista de «arrogancia» (bubris) antropocéntrica (Bennett 2009).

¿Cuáles son las posibilidades para una arqueología no antropocéntrica (Nativ 2014)? ¿Hasta qué punto pueden los arqueólogos estudiar los materiales sin humanos? En cierta forma, ya lo hacen. Mientras que los arqueólogos del siglo XX se posicionaron explícitamente en el campo de las humanidades (adyacente a la historia o a la antropología sociocultural), esta posición entró en tensión con las complejidades de la práctica arqueológica ya mencionadas. La ahora famosa discusión de Schiffer (1975) sobre las «transforms» como un medio para entender los modos múltiples en que se forma un sitio arqueológico es un caso sugerente: mientras que las transformaciones dirigidas por factores culturales o humanos (c-transforms, en su terminología) fueron importantes, también lo fueron los procesos y modificaciones provocadas por fuerzas naturales ( $n$-transforms) como los roedores, el viento, las raíces, el liquen, sales en expansión, arcillas reducidas, etc. Aunque la noción de Schiffer de $c$-transforms y n-transforms aún se basaba en divisiones tradicionales, ayudó a repensar el registro arqueológico (comparar intentos recientes en Hodder 2012, Lucas 2012). Las consecuencias implicaron un cambio, de concebir el registro como la inscripción inmediata de acciones humanas del pasado a verlo como un conjunto mixto de cosas que podría estar «depurado» en los dominios humano y no humano. Mientras que estos materiales a veces podrían estar muy enredados con las actividades e imaginaciones humanas, en otros casos podrían seguir trayectorias mucho más independientes de transformación y estabilidad.

Lo que está en juego es un análisis más atento de un mundo desordenado y no depurado (Law 2004) que incluye (pero que no es reductible a) sus habitantes humanos. Mientras que este desorden es un reto clave para cualquier investigación cuidadosa que rastree la vida humana en sus contextos más amplios, la arqueología sigue siendo un enfoque central para explorar este problema, dada su antigua atención a las cosas, los conjuntos fragmentarios y los modos en que los nunca, los inertes materiales del pasado, pueden irrumpir en el presente. 


\section{Formas de representación}

Los modos por los cuales se pueden representar las complejidades, lo desconocido e incluso los encantamientos de lo material, constituyen un área donde las recientes discusiones arqueológicas y los nuevos materialismos encuentran otros importantes puntos de articulación. En lugar de seguir el enfoque anterior en el proceso interpretativo (donde lo material tendía a ofrecer una cadena diferida de significados), la posición realista de los nuevos materialismos propone una reconsideración de las posibilidades de la representación. Aunque no siempre ha sido explícitamente presentada así, una de las contribuciones neomaterialistas más importantes ha sido la exploración de los límites productivos (en vez de limitaciones negativas) de la representación.

La lista de cosas heterogéneas, como indicio de la irreductibilidad y los límites de la representación, es un recurso narrativo recurrente en la bibliografía neomaterialista. En su influyente discurso sobre el gran apagón eléctrico de 2003 en los Estados Unidos, la teórica política Jane Bennett $(2009,25)$ enumera: «el carbón, el sudor, los campos electromagnéticos, los programas de computadora, los chorros de electrones, el ánimo de lucro, el calor, los estilos de vida, el combustible nuclear, el plástico, las fantasías de dominio, la electricidad estática, la legislación, el agua, la teoría económica, el alambre y la madera».

De modo parecido, Karen Barad (2007: 360) redacta una lista sobre el fenómeno de la microscopía de efecto túnel:

Microscopios de efecto túnel y las prácticas de microscopía, la historia de la microscopía, los avances científicos y tecnológicos posibilitados por los microscopios de efecto túnel, la teoría cuántica del efecto túnel, la ciencia de materiales, los recursos corporativos y las prácticas de investigación y desarrollo de IBM, la curiosidad e imaginación científica, la esperanza científica y cultural de la manipulación individual de los átomos, el sueño de Feynman sobre la nanotecnología, la iconografía cultural, los modos capitalistas de producir deseos, la publicidad, la producción y reconocimiento público de logos corporativos, la historia del átomo, la suposición del individualismo metafísico, los complejos conjuntos de prácticas de visualización y lectura que hacen esas imágenes inteligibles como pinturas de palabras y objetos, y las historias entrelazadas del representationalism ${ }^{1}$ y la práctica científica.

La yuxtaposición de elementos heterogéneos en estas listas sirve para subrayar una multiplicidad de actores/actantes/materiales y una apertura en las redes que constituyen el fenómeno bajo consideración. La conjunción deliberada de sueños, teorías, materiales, técnicas e historias viola los dominios establecidos de la descripción y la explicación.

Menos obvia en estas listas, pero no menos importante, es la atención a las relaciones heterogéneas y animadas entre los materiales constituyentes. Como sostiene Barad, nuestros análisis necesitan ir más allá de un mero reconocimiento de la materialidad y explorar las fricciones de las «intra-acciones» materiales. En este punto, en el paso más allá de la lista, surge el problema de las estrategias representacionales adecuadas. Una propuesta ha sido visual, por ejemplo la de Barad, quien esboza una visión de las topologías complejas que constituyen el campo socionatural, formado por la disciplina de la física cuántica (Fig. 1).

Vale la pena detenerse aquí para una comparación con una historia más larga de diagramas aparentemente similares en arqueología (Fig. 2). Clarke (1968) nos da una visión clásica desde de la teoría de sistemas de un sistema cultural coherente, constituido por subsistemas internos y su relación con el ambiente externo. LaMotta y Schiffer (2001) resitúan el foco sobre el sistema conductual, lo que les permite evitar la abstracción de segundo nivel de la «cultura». Por otro lado, Hodder (2012), reconociendo explícitamente la influencia de los arqueólogos conductuales, ha desarrollado el «diagrama de enredos» (tanglegram), que traza las circulaciones y trasformaciones de materiales en un sitio especifico (y que descentra aún más la posición de lo humano).

Esta revisión breve nos lleva al importante (aunque bien conocido) problema de cómo elegir los niveles de escala y complejidad en nuestros modelos. El diagrama de Barad, por otro lado, parece 


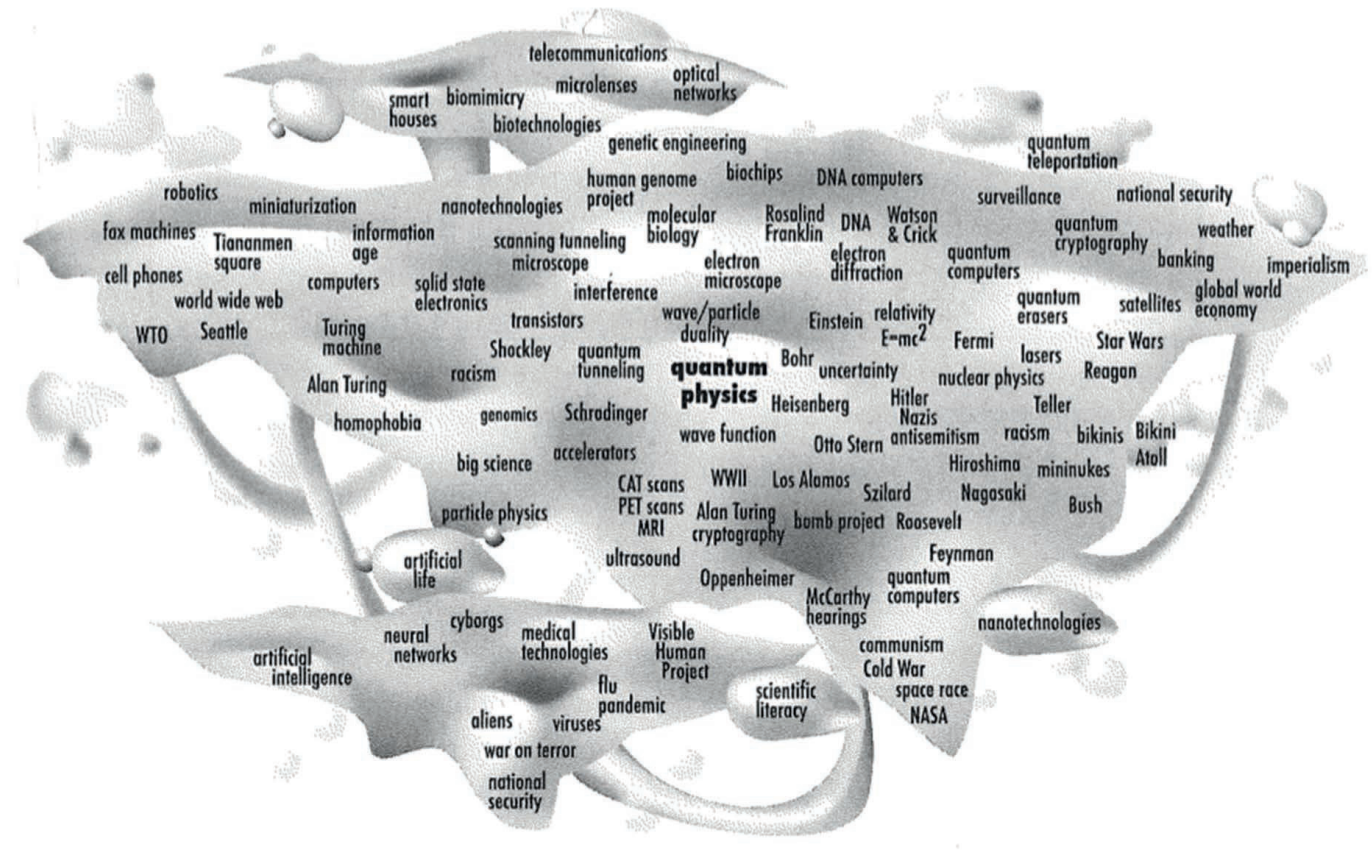

Figura 1. Diagramando la topología de la física cuántica (Barad 2007: 389).

apuntar en otra dirección, enfatizando las insuficiencias de nuestras formas representacionales (2007: 389). Tal como explica la autora, cuesta expresar las calidades dinámicas, multiescalares y relacionales del fenómeno bajo estudio. Dado este énfasis en las dificultades de una explicación adecuada de los objetos en toda su complejidad relacional, ¿es acaso el resultado clave que redunda negativo lo que queda más allá de la representación (v.g. Bennett 2009 siguiendo Adorno)? ¿O podemos tomar la perspectiva un poco más optimista de Latour, según la cual si bien «todavía no sabemos cómo reunir, en un espacio singular y visualmente coherente, todas las entidades necesarias para que una cosa se convierta en objeto... cuando hayamos aprendido cómo hacerlo, podríamos finalmente recuperar nuestro materialismo (material)» (2007: 142?).

Sostendría que debemos aceptar que «nuestros conceptos y patrones de pensamiento luchan con la naturaleza profundamente procesual de las cosas» (Dupré 2012: 8) y que el ideal de un nuevo «espacio singular y visualmente coherente» nunca será alcanzable. Al mismo tiempo, la lucha contra el «desorden» (Law 2004) de los materiales y sus vitalidades — tan visible en los diagramas imperfectos de los arqueólogos y otros- puede ser productiva en tanto expulsemos nuestros modelos «de sentido común» sobre el mundo. El resultado no es ni un singular espacio representacional ni la provocativa, pero en última instancia estéril, evocación de lo negativo más allá del espacio representacional. En cambio, obtenemos múltiples escalas irreductibles, una mayor conciencia de los límites de representación y la voluntad de aceptar regímenes híbridos de rastreo, muestreo y la generación de imágenes para enfrentarse a estos límites.

Si reducimos la velocidad de nuestra perspectiva sobre la práctica arqueológica y ponemos en duda una división fácil entre el «sitio real» y el «informe representacional», podemos empezar a reconocer los modos en que los productos de esta práctica ya encarnan una serie de compromisos mucho más complejos. Como cualquier otra ciencia social, la arqueología produce un corpus creciente de textos. Pero también produce, transforma y vincula una serie heterogénea de bases de datos, fotos, mapas, dibujos de campo y colecciones de materiales (Webmoor 2007). Rasgos 

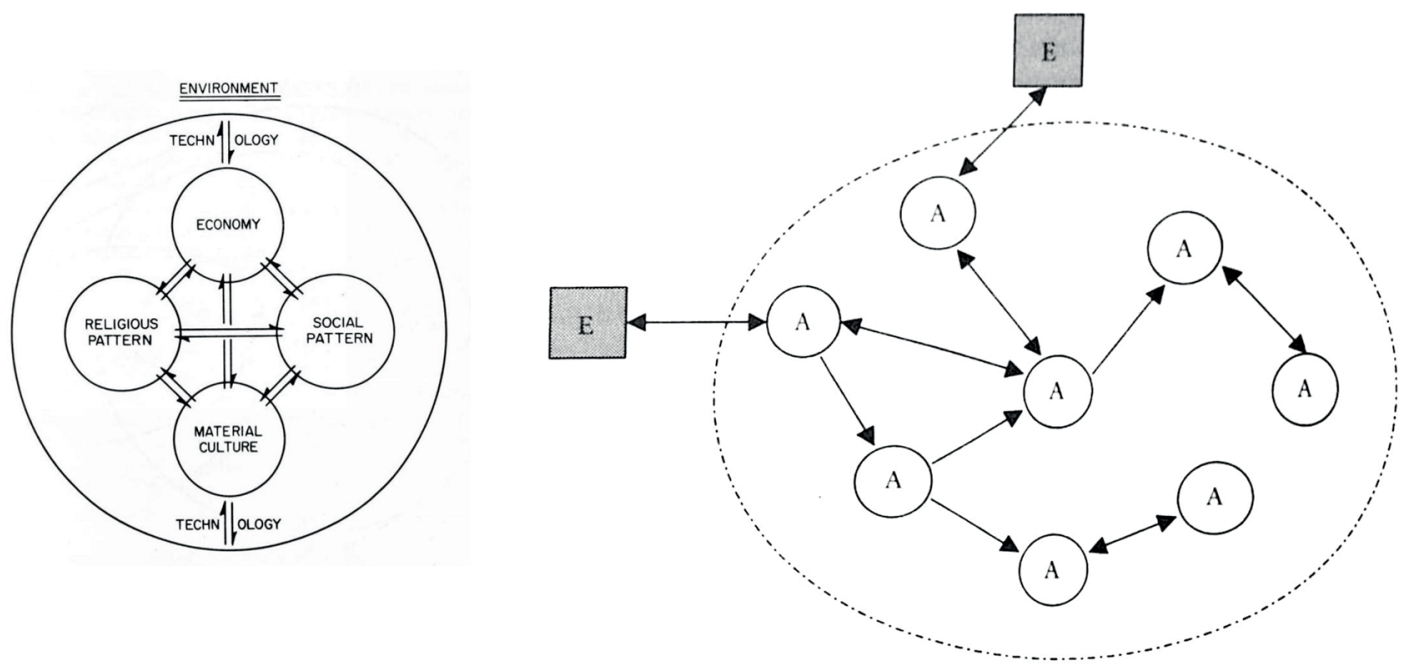

KEY: A Activity
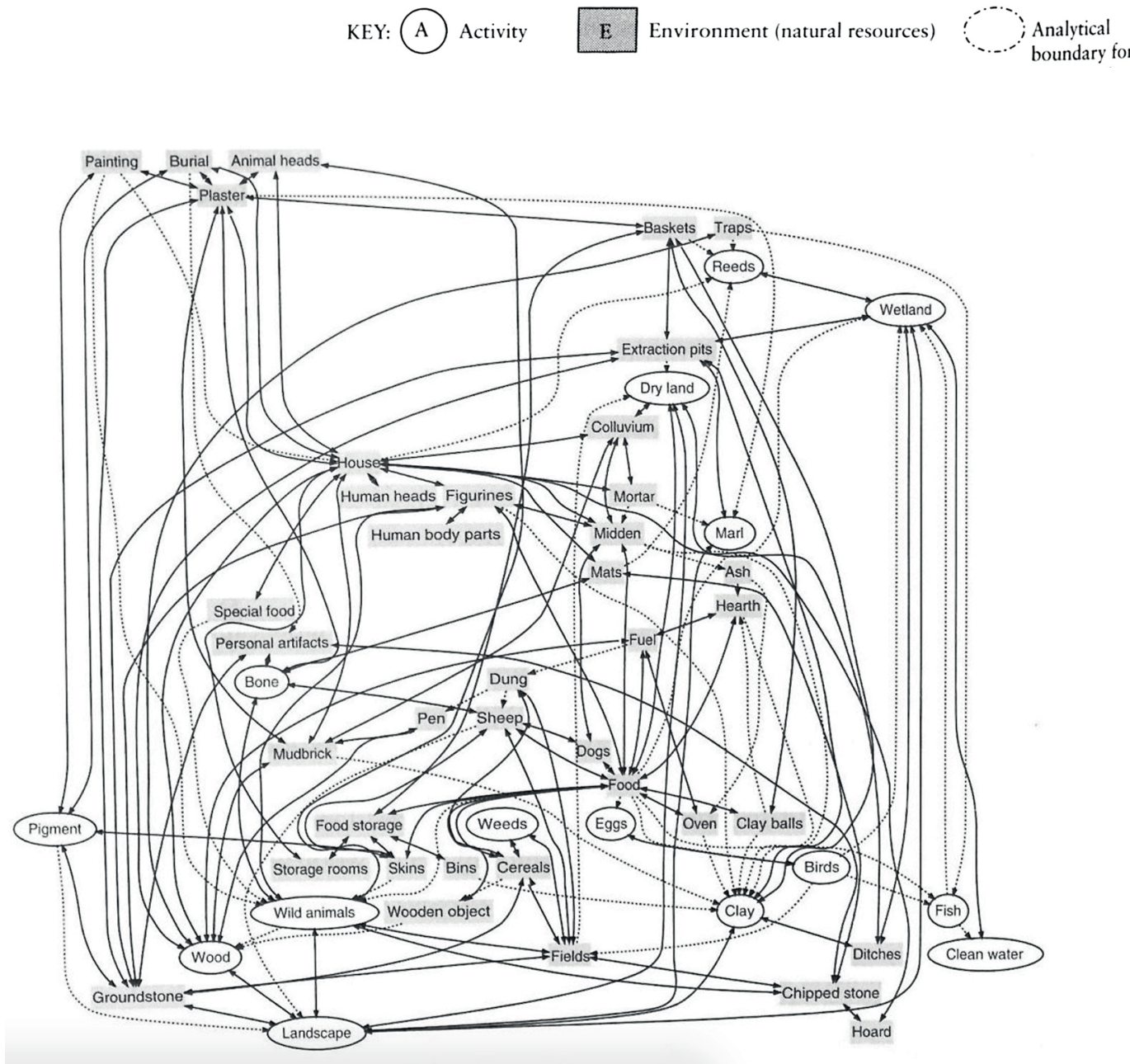

Figura 2. Diagramas arqueológicos (Clarke 1968; LaMotta y Schiffer 2001; Hodder 2012). 
arqueológicos, artefactos y sitios forman conjuntos que devienen nuevas formas a través de estos modos activos, e incluso performativos, de producción y transformación (Shanks 2004), más que existir como objetos pasivos e inertes. A través de las prácticas productivas de trazar, separar, agrupar y cuidar estos conjuntos, el trabajo arqueológico se mueve de una forma particularmente conspicua más allá de los regímenes de significación para incluir la representación y el índice junto a las calidades independientes del observador. Tal vez a causa de la serie de brechas entre el observador y lo observado en el encuentro arqueológico (v.g. presente-pasado, humano-no humano, totalidadfragmento), los arqueólogos han tendido más hacia un reconocimiento realista de esos materiales y rastros que existen más allá del régimen cerrado de significación (Ginzburg 1979; Hodder y Hutson 2003; García 2014).

Aparte de estos modelos de una práctica «más que representacional» (Vannini 2015) que la arqueología podría ofrecer, el problema de la representación en su sentido político-ético también merece consideración. ¿Cuáles son las cosas que importan? ¿En quién (y dónde nos) apoyamos? ¿Qué actores están representados? Estas son preguntas y compromisos que, si bien a veces quedan marginalizadas en los círculos arqueológicos, son una contribución central de las intervenciones de la ecología política ya mencionadas.

En parte, un reinvolucramiento neomaterialista con la tradición de la economía política plantea preguntas de praxis y afecto. La investigación comprometida como crítica política tiene una larga historia en las ciencias sociales; como señala Sayer (2000), existe un modelo subyacente (usualmente tácito) basado en identificación de un problema y sus causas, el juicio negativo de esas causas y la exigencia de acciones positivas para eliminarlas. Sin embargo, en el contexto de un empobrecimiento de la crítica por su sobreidentificación con una "hermenéutica de desconfianza» y un declive en la aspiración utópica (Latour 2004; cf. Braun y Whatmore 2010), varios han exigido recientemente una reevaluación de esta forma de intervención intelectual. Por lo tanto, los neomaterialistas han recurrido a las vitalidades (Coole y Frost 2010) y el reencantamiento (Bennett 2009) como bases para intervenciones que amplíen el compromiso de actores políticos y alientan nuevas sensibilidades afectivas hacia este compromiso.

En resumen y a riesgo de parecer vagos y crudamente pragmáticos, podríamos pensar en tres momentos en las estrategias representacionales neomaterialistas: la lista (esbozando una visión inicial, evocativa y afectivamente cargada de la diversidad de materiales a mano), el diagrama (un rastreo más forense de indicios que sugieren las clases y topologías de relaciones, influencias y fuerzas) y el conjunto (el desarrollo de nuevas jerarquías de interés, sitios y objetos, con el objetivo de posibilitar nuevas formas de compromiso). Estas estrategias demuestran los impactos potenciales de las perspectivas neomaterialistas para cómo conceptualizamos la práctica, la ética y los objetos de nuestros estudios en la arqueología. En la sección que sigue quisiera explorar estos impactos potenciales en una manera más concreta con un caso de estudio en la arqueología histórica de los Andes sur-centrales.

\section{Vivir de viaje en los Andes sur-centrales}

La arqueología andina tiene una tradición larga e importante de análisis materialistas, notablemente la arqueología social en el Perú (Lumbreras 1984; Tantaleán 2006) y la economía política norteamericana (Earle 1993). Después del tumulto teórico de los años noventa, surgió un nuevo interés en la materialidad y en análisis materialistas, que incluye los trabajos recientes de los «neoanimistas» en la región (Alberti 2007; Lau 2010; Weismantel 2015). Aquí busco explorar un nuevo territorio, alineándome con un enfoque emergente sobre la ecología política (v.g. Wilkinson 2013) y viendo los implicaciones para la arqueología histórica de la región.

Ubicada en la frontera sur del territorio peruano moderno, la sierra de Tacna y Arica representa el tipo de paisaje rural marginal frecuentemente omitido en el análisis de los períodos coloniales 
y republicanos. A pesar de esta falta de atención, los valles Azapa y Lluta (Arica, Chile) y Caplina (Tacna, Perú), fueron históricamente importantes como vía de comunicación entre la costa pacífica y el altiplano boliviano. En 2015, el Proyecto de Investigación Arqueológica Tambos de Palca examinó la historia del movimiento en el valle del Caplina, enfocandonos en el área de transición entre las topografías costeńas y altiplánicas, donde la altitud asciende a $4200 \mathrm{msnm}$ en un transecto de 30 kilómetros (véase Chauca Iparraguirre 2016; Corcoran-Tadd 2017 para discusiones más detalladas y tradicionales del proyecto). Investigaciones subsiguientes por el autor en la cabecera del río Lluta continuaron explorando este paisaje, registrando hasta la fecha un total de 18 tambos (prehispánicas y coloniales).

Estos valles formaban rutas secundarias durante el incanato, conectando los centros altiplánicos con la zona precordillera y el litoral pacífico (Williams et al. 2009). Con el auge de las ciudades altiplánicas de Oruro, Potosí y La Plata, asociadas al boom minero durante los siglos XVI y XVII, los valles se transformaron en las vías esenciales hacia la costa (Fig. 3), formando parte de la ruta de la plata (López Beltrán 2016). En el siglo XIX se dieron cambios importantes, cuando la región se transformó en un foco para la extracción y el procesamiento de plata, cobre y azufre a menor escala. Actualmente cortadas por los límites modernos del Perú, Chile y Bolivia, las rutas están marcadas hoy por un conjunto de sitios arqueológicos (campamentos con sus paravientos y fogones, tambos con sus muros de tapia y adobe) ubicados a lo largo de segmentos abandonados de caminos.

Mientras que la prospección arqueológica indica una larga historia de movilidad en este paisaje antes de la expansión incaica, la inversión infraestructural durante los períodos incaico colonial y republicano temprano en los caminos y los tambos, señaló una gran intensificación y formalización del tráfico. Actualmente, los estrechos y áridos valles de la sierra tacneña y ariqueña manifiestan la presencia discontinua de este tráfico, con tambos en varios estados de colapso, dada la erosión de los muros de adobe y tapia a causa del impacto combinado de las lluvias estacionales y la construcción de nuevas carreteras (Fig. 4). Dispersiones de cerámica, líticos, vidrios, pedazos de mineral, huesos de animales, herraduras, balas, capas de estiércol y fragmentos de plástico, indican la ocupación recurrente de estos espacios por actores humanos y no humanos a través de los últimos cinco siglos.

Este caso de estudio (que deriva de una investigación más amplia sobre la arqueología histórica en Tacna y Arica) se articula con la discusión teórica previa, tanto con la problemática de lo natural como con la problemática de lo político. En primer lugar, dada su posición fronteriza entre los dominios disciplinarios, la arqueología histórica tiene una relación particularmente tirante con lo material y lo natural. Muchas investigaciones en la arqueología histórica siguen implícitamente la declaración de James Deetz según la cual «mientras la cultura se complejizaba, nuestro retiro del mundo natural se aceleró. Dado que la Arqueología Histórica investiga solamente los últimos siglos de nuestro pasado de millones de ańos, se deduce que este último breve período nos encontraría en nuestro mayor retiro de la naturaleza» (Deetz 1977, 22). Mientras que intervenciones posteriores pusieron seriamente en duda esta visión (Mrozowski 2006), mucho de la arqueología histórica continúa ubicándose en una perspectiva más tradicional sobre los sujetos de la historia. ¿Pero es lo material el foco de la investigación o es, más bien, un barniz sobre descripciones mayormente archivísticas? ¿Qué tal si contradecimos a Deetz y a otros, con el reconocimiento fundamental que el «mundo natural» nunca se retiró del «mundo humano»?

En segundo lugar, la proximidad de los pasados investigados por la arqueología histórica con el presente, ofrece varios problemas adicionales. A pesar de (o debido a) la profusión de datos (textuales, fotográficos, materiales, ambientales) raramente disponibles para los arqueólogos que trabajan en períodos más tempranos, los arqueólogos históricos han tendido a mantener modelos conservadores de causalidad histórica. Este conservadurismo teórico está probablemente reforzado por los posibles significados políticos de esos pasados recientes. Del mismo modo, a la par que las ontologías «más planas» parecen poco problemáticas para el estudio de casos en la prehistoria remota (v.g. Knappett 2011; Hodder 2012), sus aplicaciones en la época moderna son potencialmente 


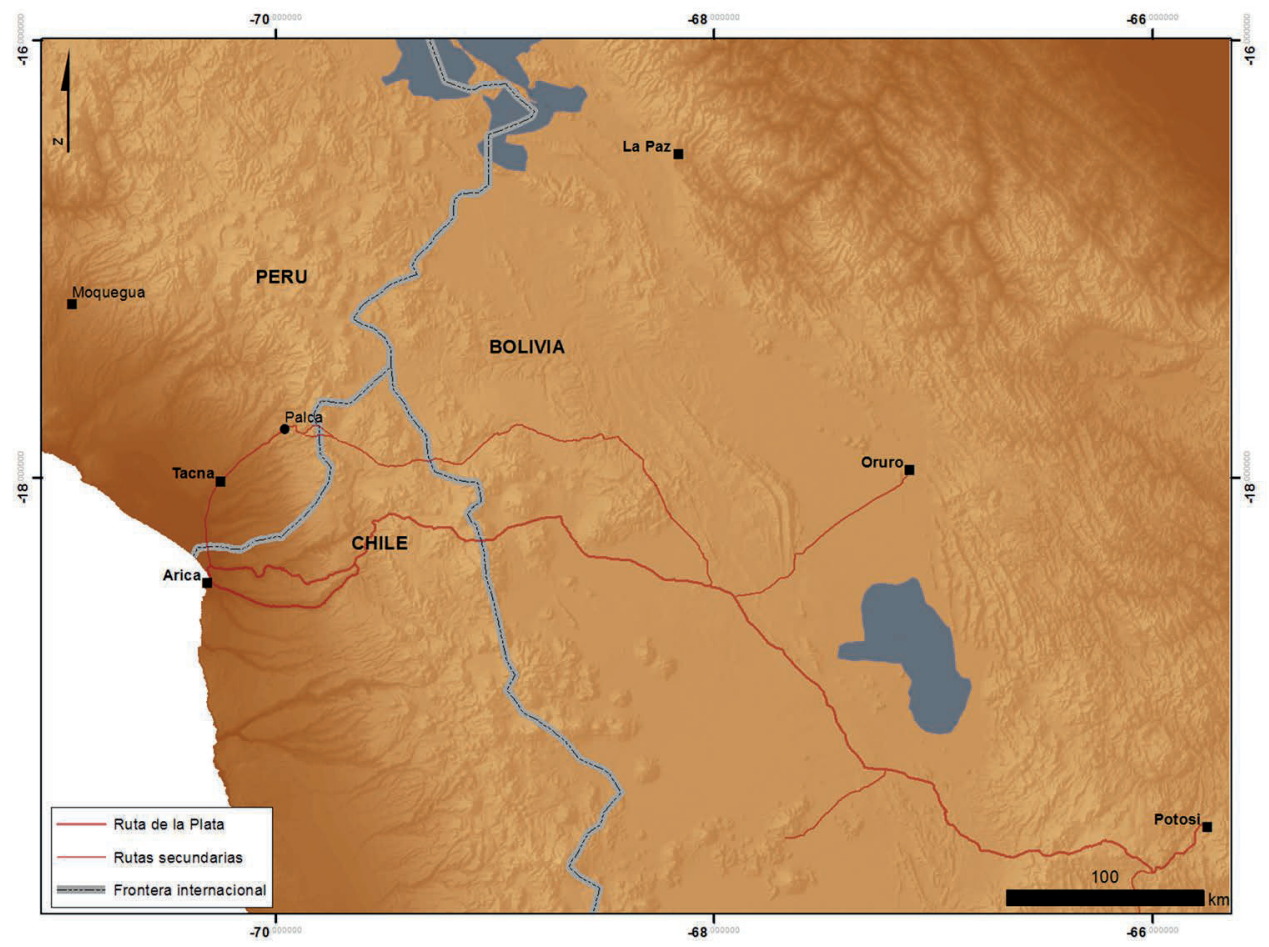

Figura 3. Mapa de 'la ruta de plata' y su contexto (Obra del autor).

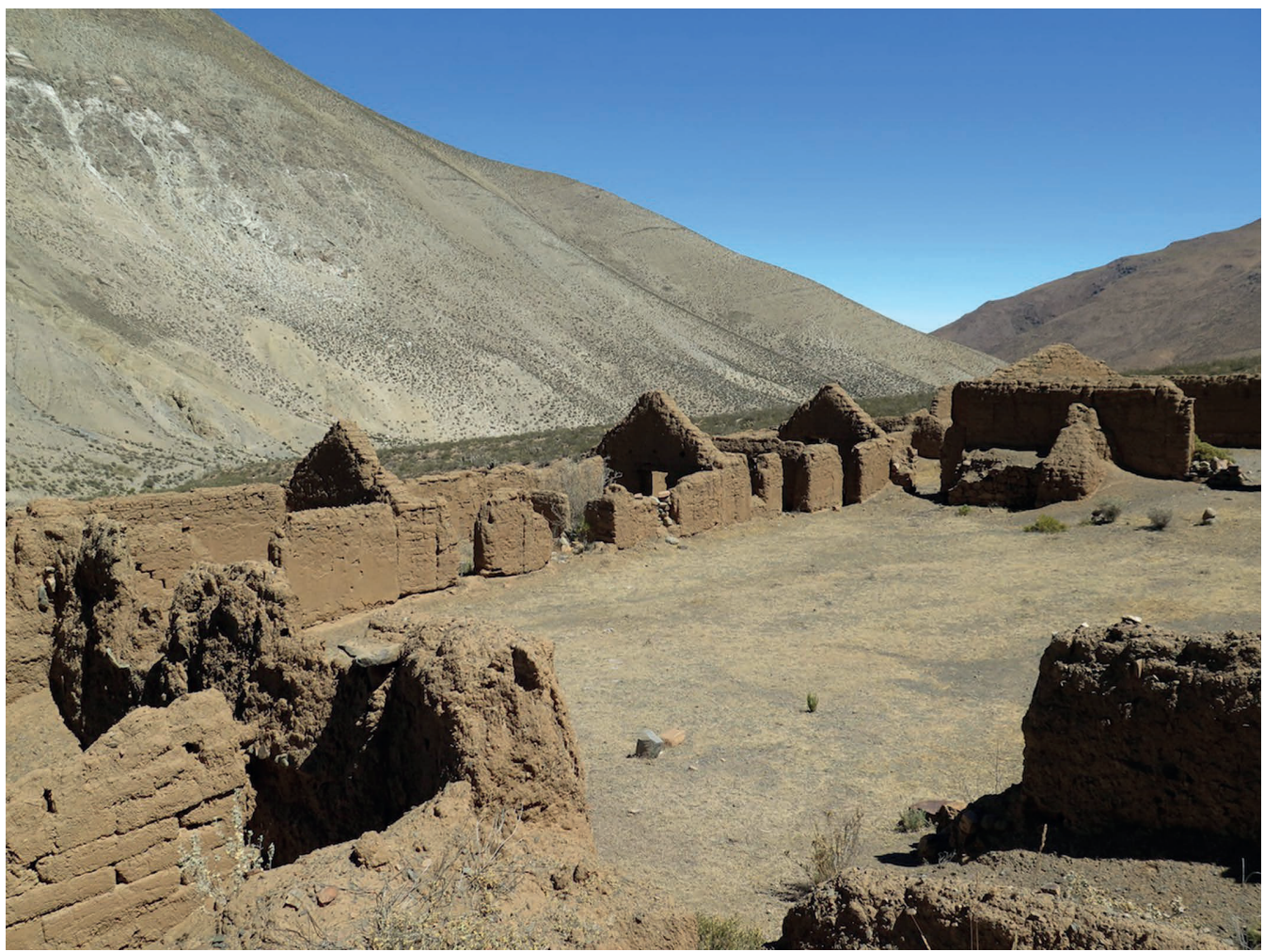

Figura 4. Tambo Libertad A (siglo XIX), Tacna (Foto del autor). 
mucho más tirantes. Si los actores humanos están desplazados de sus posiciones tradicionales en las historias del colonialismo, el capitalismo y la esclavización, ¿desaparecerá la base para la crítica entre la proliferación de nuevos actantes (Collins y Yearley 1992; Fowles 2010)? ¿O habilitan estos nuevos planteamientos una perspectiva más clara del proceso histórico que va más allá de las reducciones atractivas, mientras que también se conserva una postura crítica sobre la violencia estructural y las desigualdades de los últimos cinco siglos?

En una intervención a favor de la segunda posición, quisiera exponer los modos en que una atención a lo ordinario y lo no humano puede proveer una perspectiva nueva, aunque siempre crítica, de la logística colonial a través de una exploración de las vidas asociadas a los caminos. En los análisis históricos tradicionales, los caminos entre el altiplano y la costa fueron tomados como componentes que encajaban en narrativas ya existentes conectando nociones de «lo colonial» con «lo económico» y «la globalización». Así, el foco se ubica casi siempre en el movimiento de la plata entre las ciudades mineras del altiplano a través de los espacios vacíos y abstractos del paisaje rural, y hacia las ciudades portuarias del Pacifico. Un historiador social podría ańadir muchos matices basados en las fuentes escritas sobre las relaciones laborales en disputa y las identidades sociales de algunos actores a lo largo de la ruta. No obstante, las ontologías implícitas en estas descripciones siguen siendo muy básicas, con cuerpos (humanos) universales moviéndose en un espacio abstracto y todos impulsados por una serie de imperativos que funcionan como «cajas negras». Aquí, lo material está en juego frecuentemente solo como la mercancía (de hecho, la denominación de la «ruta de la plata» constituye una reducción ilustrativa de la ruta a un solo material). Sin recurrir a un empirismo ingenuo que ignora las lecciones del realismo crítico sobre la escala y el rastreo de estructuras causales subyacentes (Sayer 2000), una mirada más atenta al sitio concreto y la región marginal contrarresta previas relaciones críticas, pero relativamente abstractas de los Andes coloniales.

Comienzo esta visión alternativa con la experiencia corporal en el campo de trabajo arqueológico. Después de varias temporadas de investigación caminando lentamente y sistemáticamente por las rutas de Tacna y Arica, he podido apreciar las calidades particulares de su topografía y los efectos que tienen sobre los cuerpos humanos. Aunque soy consciente de las críticas importantes al giro fenomenológico en la arqueología de hace varias décadas (por ser demasiado visual, por ignorar la diferencia corporal, por ser ahistórico), seguiré a Oscar Aldred (2014) en su reconocimiento del papel que desempeña el movimiento corporal a través del sitio acerca de la comprensión de la movilidad en el pasado. En particular, la experiencia en el campo y su yuxtaposición con materiales arqueológicos y archivísticos ha subrayado los modos en que la movilidad a lo largo de la ruta de la plata fue moldeada por múltiples factores «socionaturales» que nos llevan más allá de las historias sociales convencionales de la economía política colonial, y hacia un nuevo análisis neomaterialista.

\section{Movilidad basada en las múltiples vitalidades de cuerpos que trabajan}

Con sus orígenes en el pasado prehispánico y continuando hasta el presente, los porteadores humanos y animales han sido componentes fundamentales en las redes de transporte en la sierra andina. Mientras los vehículos de ruedas proliferaron en la costa durante el período colonial, los extremos topográficos en la sierra fomentaron la persistencia de regímenes de porteros y caravanas hasta el siglo XX. Los músculos de las llamas, los cascos de las mulas y las espaldas humanas conformaron las bases para las incursiones iniciales de Pizarro y Valdivia, la articulación del sistema de encomiendas y el eventual surgimiento de las redes que conectaron las grandes minas de plata del Alto Perú con los mundos del Pacifico y del Atlántico.

En vez de seguir las particiones estándares de la historia social, es revelador considerar las formas en las que el trabajo humano, mular y camélido fue organizado y explotado en combinación; en configuraciones que fueron frecuentemente sujeto de negociación legal y extralegal ( $c f$. Mikhail 2013 para una discusión del trabajo animal en el caso paralelo de Egipto moderno temprano). En 
estos proyectos de sustitución laboral, los papeles relativos a viajeros y comunidades locales, indios y africanos, mulas y llamas estuvieron en constante disputa (Corcoran-Tadd y Pezzarossi 2018). Los modos en que las vitalidades de estos cuerpos pudieron (o no) ser captados y desplegados para movilizar otros humanos y materiales fueron puestos en juego.

Esta multiplicidad de actores fue particularmente visible durante el registro de los tambos mismos. A pesar de la tendencia de ver estos sitios como instalaciones para viajeros, en los planos arquitectónicos de los tambos de Tacna y Arica predominan los espacios (corrales, patios y portones) destinados para los animales de carga. Algunos tambos en Tacna (v.g. Copapuquio, Libertad B) también están rodeados por áreas de andenería, probablemente empleadas para el cultivo de alfalfa para forraje (reflejando la transformación mucho más masiva durante la colonia de los maizales del valle Caplina en uno de los paisajes claves para la producción de la alfalfa (Cavagnaro 1988)). Hoy en día los camélidos, cabras y ganado siguen ocupando los tambos, en unos casos bajo el cuidado de pastores que han reocupado sectores de los patios, y en otros pastando solos en las alturas. Además de las abundantes capas de estiércol que forman los nuevos pisos de estos sitios, los muros también evidencian huellas de la presencia de animales que fuerzan nuevas entradas y desgastan la tapia y adobe mientras se resguardan del frío.

\section{Movilidad influida por los efectos diferenciales del ambiente de gran altura}

Más allá de las vitalidades humanas y no humanas, tenemos que tener presente los efectos de la topografía altoandina. El padre jesuita José de Acosta $(1590,143)$ proporcionó un llamativo relato sobre «una congoxa tan mortal» por soroche (mal de altura) al atravesar la cordillera, mientras que el viajero del siglo XIX, E. G. Squier describió el efecto similarmente brutal de la altitud sobre las mulas específicamente en el punto más alto de la ruta de Palca: «trabajando fuertemente nuestras mulas y parándonos brevemente para tomar aliento, llegamos al abra de Guaylillos, marcado, como en todas las abras altas del Perú, por una apacheta o hito de piedra, levantado por los indios, cada uno de ellos lanzando una piedra o mascada de coca. Esta apacheta mide aproximadamente veinte pies, coronada por una cruz rudimentaria y cubierta en sus faldas por los esqueletos y cuerpos secos de mulas que murieron aquí bajo la influencia del soroche» (Squier 1877, 248).

El siglo XX fue escenario de una gran cantidad de investigaciones sobre las adaptaciones de altura realizadas por médicos y antropólogos, quienes vieron en los Andes Centrales un laboratorio excepcional para examinar los límites del cuerpo humano (Monge 1937). Se estableció que los efectos de la altura comienzan a manifestarse fuertemente a partir de los $3000 \mathrm{msnm}$, siendo los Andes Centrales y el Himalaya en Asia las únicas áreas con poblaciones importantes a estas alturas (Beall 2014). En ambos casos, las poblaciones indígenas se han adaptado a las durezas de la hipoxia y el frío a través de una mezcla compleja de comportamientos, aclimatación, efectos del desarrollo durante el ciclo vital y cambios genéticos. Al nivel fenotípico, estas adaptaciones aparecen en varias escalas y, en las poblaciones andinas, incluyen rasgos como un elevado volumen pulmonar residual, elevadas concentraciones de hemoglobina y un elevado peso al nacer.

Los impactos que esta topografía puede tener sobre el cuerpo humano fueron sufridos en muchas ocasiones en el campo de manera dolorosa por los miembros costeńos de nuestros proyectos, condiciones que afectaron fuertemente la logística y el ritmo de nuestros trabajos. Sin embargo, los impactos de estas adaptaciones a la altura (de corto y de largo plazo) han sido poco discutidos por arqueólogos e historiadores del período colonial. Históricamente, la región andina ha sido abordada desde marcos explicativos reduccionistas que buscaban relaciones deterministas entre la cultura, la raza y/o el ambiente (Gotkowitz 2011). El reto entonces es construir un marco adecuado para explicar las relaciones históricas entre las diferencias corporales y los ambientes extremos de los Andes sin caer en posiciones ni de un construccionismo fuertemente social, ni de un determinismo natural. 


\section{Movilidad «enredada» con (pero no determinada por) jerarquías de diferencia corporal}

Regresando al archivo colonial, se encuentran pleitos recurrentes sobre los regímenes de trasporte que hacen referencia frecuente y explícita a las calidades diferentes de trabajadores humanos y no humanos con respecto a sus capacidades para el trabajo y la reproducción a gran altura (Cobo 1890 [1653], Cook 1981). Las mulas, con su mayor capacidad de carga (70-100 kilogramos en comparación con 25-60 kilogramos para camélidos (Roth 1999, Tripcevich 2007)), fueron la opción cada vez más elegida para el trabajo de transporte en muchas áreas durante el período colonial. Las diferencias adaptativas de largo plazo perduraban, sin embargo, persistiendo las caravanas de camélidos en muchos contextos serranos y las mulas en los ambientes cálidos y áridos de la costa (Sanhueza 2011). En algunos casos, los viajes de caravana tuvieron composiciones de especies múltiples, con una transferencia de cargas entre mulas y camélidos en puntos claves de altura.

Esta situación fue parcialmente en paralelo con el impacto de la movilidad vertical sobre la salud indígena. El rápido movimiento de trabajadores humanos adaptados a ambientes costeńos y serranos a nuevos ambientes parece haber tenido impactos verdaderos sobre los cuerpos indígenas, particularmente a través de infecciones respiratorias y vasculares (Cook 1981, 156). Asimismo, aunque proporcionan una perspectiva imperfecta, las repetidas expresiones legales halladas en el archivo de preocupación sobre estos impactos (v.g. Vaca de Castro 1908) son sugerentes acerca de las tensiones persistentes entre un discurso de protección y un pragmatismo de los regímenes laborales coloniales, que buscaron aprovechar las capacidades corporales de poblaciones altiplánicas.

Mientras que estas disputas sobre cuerpos que trabajan fueron frecuentemente expresadas utilizando discursos altamente problemáticos de diferencia proto racial y diferencias de especies, dudo en entenderlas como meros productos del discurso cultural. Al contrario, quisiera enfatizar cómo ciertas capacidades para el movimiento y el trabajo a grandes alturas fueron movilizadas y valorizadas en un proceso de la colonización de cuerpos locales (poblaciones y camélidos indígenas) y la importación de los cuerpos ajenos (africanos, españoles, équidos). Del mismo modo, en lugar de tomar estas capacidades como esenciales, sería vital explorar los modos en que surgieron durante múltiples escalas de tiempo (aclimatación de corto plazo, presiones selectivas de largo plazo (ver Beall 2014)) y los modos en que llegaron a importar (o no) como blancos de explotación y como fuentes de resistencia. Como ha notado Susan deFrance (2010) en su análisis de colecciones zooarqueológicas previas y posteriores a la conquista en los Andes sur centrales, los regímenes coloniales de transporte fueron mucho más duros para los camélidos, haciendo visibles los límites de sus cuerpos en formas que previamente habían sido irrelevantes. Además, mientras se registra una presencia estacional de camélidos en la costa chilena durante el período prehispánico tardío (Sanhueza 2011), la nueva estacionalidad del transporte colonial provocó nuevas dificultades para las caravanas de camélidos y contribuyó a su retirada hacia la sierra.

Es importante remarcar que este estrés y su inscripción violenta sobre los cuerpos que trabajan podrían atribuirse a sus causas no humanas directas (altitud, diferencia corporal, topografía). Pero como ha seńalado Jason De León (2015) en su exploración pionera sobre la migración y la muerte en la frontera entre los Estados Unidos y México, este aplazamiento de la causalidad a la «naturaleza» es también un acto político que deriva su fuerza a través de su explicación (parcial) de un conjunto mucho más amplio de materiales y estructuras.

\section{Movilidad mediada por la presencia y mantenimiento de infraestructura}

Hay que recordar también que el hacer y el deshacer de la vida en el camino tenía su contexto más amplio de la techné (en el sentido de la movilización de técnicas productivas) - «divorciado de las cosas que constituyen la vida humana como tal, la biopolítica viene a expresarse, en cambio, en términos ahistóricos y metafísicos, incapaz de explicar el séquito de objetos y conocimientos tecnológicos que condicionan las vitalidades de los cuerpos y que las deja sujetas al cálculo político» 

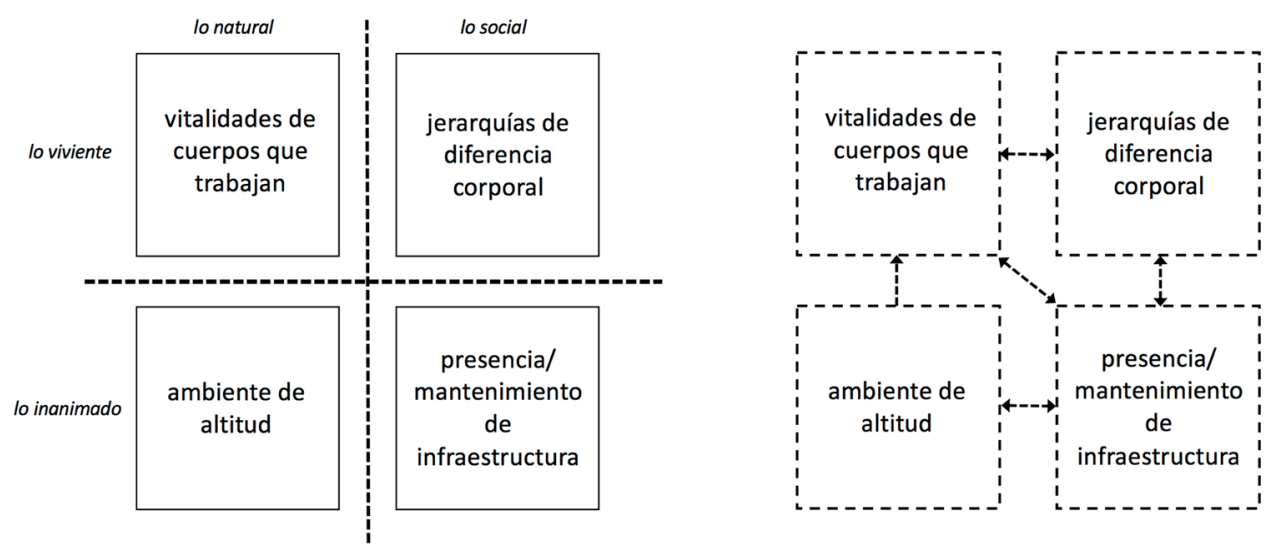

Figura 5. Diagramando la movilidad colonial (obra del autor).

(Braun y Whatmore 2010, xi). Las capacidades corporales para el trabajo en los extremos del paisaje serrano podrían ser modificadas fundamentalmente con la construcción, el mantenimiento y el colapso de la infraestructura vial (caminos, tambos y puentes).

Como ya fue señalado, no es cosa fácil atravesar la sierra de Tacna y Arica a pie. Con temperaturas que caen bajo cero, vientos fuertes, poca disponibilidad de agua y una ausencia de asentamientos significativos, la infraestructura de los tambos proporcionaba un sustento decisivo para los viajeros humanos y animales. Los corrales de pirca y tapia, la carne de camélido trinchada y las botellas de alcohol (cuyos restos predominan en los contextos de los tambos a lo largo de la ruta), se juntaron para hacer posible el movimiento de masas de caravanas y viajeros (Fig. 5). La ubicación de los tambos históricos en la región de Palca es indicativa en este contexto, agrupándose entre 3000 y 4200 msnm, el punto de mayor inflexión en las gradientes entre las topografías costera y altiplánica. Tanto los humanos como los animales sufren particularmente en este tramo de la ruta, y los tambos pueden interpretarse como una manera de amortiguar los excesos de este ambiente. Surgiendo de formas arquitectónicas previas de viviendas y corrales prehispánicos, los tambos incas y coloniales conformaron importantes resguardos para sostener cuerpos laborales valiosos.

En el impredecible y dinámico paisaje de los valles serranos impactados por lluvias fuertes, sequias y terremotos, fue necesario un trabajo constante para mantener transitables los caminos. Hasta fines del siglo XIX (y en algunos casos hasta el siglo XX), el mantenimiento de los caminos persistía como un objetivo clave para el trabajo indígena obligatorio en zonas rurales (Larson 2004). La ruta de Palca no fue una excepción: un informe de 1900 detalla un proyecto sustancial que dependió del trabajo forzado y de mulas para reparar el camino después de una lluvia particularmente fuerte (AHVD 31 1893-1900, 20-34).

Arqueológicamente se puede trazar esfuerzos paralelos en los muros de los tambos con sus estratigrafías horizontales de colapsos y reparaciones. El entrelazamiento de la infraestructura y la vida móvil es particularmente evidente en su deterioro ( $c f$. Urton 1988). Con las transiciones hacia las motocicletas locales y los camiones de larga distancia a fines del siglo XX, se mataron a las mulas, los rebaños de camélidos disminuyeron y los caminos y tambos en la región fueron abandonados a los procesos erosivos que constantemente los habían amenazado (Julian Quispe, comunicación personal, $c f$. Harvey y Knox 2012). En este sentido, el desarrollo y cuidado de la infraestructura se junta con la creciente lista de factores irreductibles a «lo natural» $\mathrm{y}$ «lo cultural» (como también el ambiente, las vitalidades de los animales y los humanos, las cargas, los horarios, las jerarquías legales) que configuraban la precariedad de la vida en los caminos de los Andes coloniales y poscoloniales. Como sugiere la figura 6 , cada uno de estos factores sale en la nueva perspectiva neomaterialista con sus interrelaciones que violan los dominios analíticos tradicionales. 
Figura 6. Hueso de camélido recuperado en un basural de cocina, Tambo Libertad A (siglo XIX) (Foto del autor).

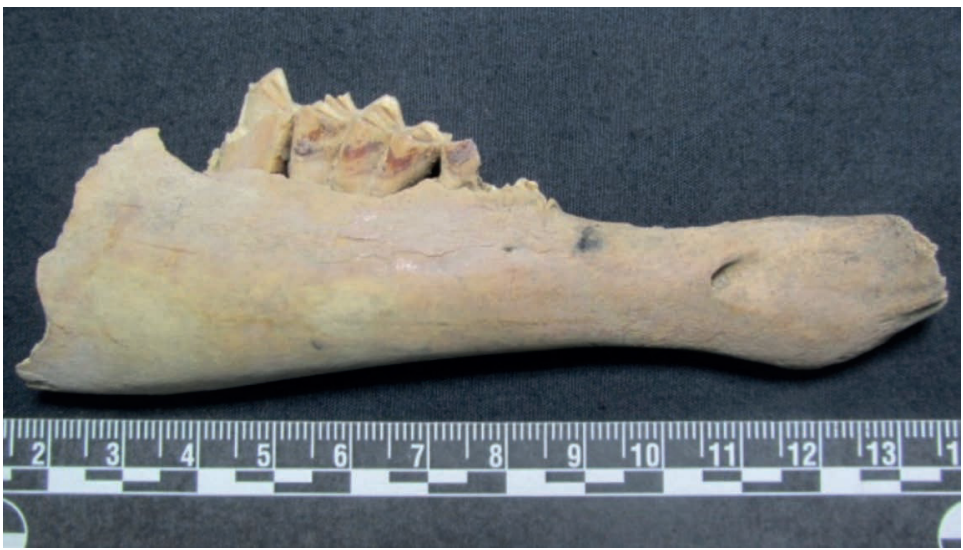

\section{Reflexiones finales}

Este esfuerzo por explorar una perspectiva neomaterialista sobre regímenes de movilidad en la sierra tacneña y ariqueña se puede contextualizar en una discusión teórica más amplia en la arqueología contemporánea acerca de la movilidad y paisajes de movimiento. Sin embargo, con un enfoque sobre los espacios topográficamente y socialmente «difíciles», el estudio de caso también discrepa significativamente de estas discusiones actuales. Mientras Chris Tilley (1994), Tim Ingold (2000) y Oscar Aldred (2014), por nombrar algunos ejemplos arqueológicos, han propuesto discusiones importantes sobre la movilidad y su materialidad, las consideraciones resultantes son notables en su evocación de un movimiento armonioso. Sin caer en «el masoquismo de la dominación» que caracteriza algunos trabajos menos cuidadosos sobre contextos coloniales, una atención a la movilidad como trabajo y a la «vida letal de la logística» (Cowen 2014) sirve de contrapeso importante.

Habiendo dicho esto, la dispersión de la causalidad histórica que caracteriza esta y otras narrativas neomaterialistas también plantea las acusaciones ya mencionadas sobre el desmantelamiento de la base para un compromiso crítico. ¿Acaso la adición del trabajo animal, el oxígeno, la hemoglobina y la lluvia a la historia de la vida en el camino conduce a dispersar (en un marco ontológico aplanado) las responsabilidades que de otro modo serían claves para una historia crítica de lo colonial? ¿O reconoce las complejidades de un paisaje e historia singular (en un marco ontológico más plano) que ilumina el papel de la violencia y la coerción mientras evita una simple hermenéutica de la desconfianza? Argumentando a favor de la segunda posición, quisiera sostener que el resultado es una narrativa histórica más compleja y enriquecida, que renueva cuestiones importantes sobre nuestras jerarquías de interés (tanto analíticas como éticas): ¿qué importa? ¿Quién importa? ¿Y para quién?

Las jerarquías de interés actuales se reflejan en el puesto en valor de valor de patrimonios regionales. Los principales sitios patrimoniales en Tacna hoy, por ejemplo, son los petroglifos prehispánicos de Miculla, que narran un pasado distante y bastante «armonioso», y el campo de batalla del Alto de la Alianza (1880), que monumentaliza un nacionalismo forjado en la violencia de la guerra industrial (Fig. 7). El resultado es una elisión de «la materia intermedia» (andenería prehispánica, redes de caminos coloniales, paisajes mineros del siglo XIX, retenes chilenos abandonados, etc.). Sin embargo, los proyectos de desarrollo (impulsados por los booms actuales de minería e infraestructura en los Andes) chocan cada vez más con esta «materia» que resuena con las visiones y la violencia de proyectos políticos y auges de los productos básicos. Con un toque de ironía, los tambos de Palca fueron registrados por primera vez en una obra de rescate por mitigar el impacto de la nueva mina de oro de Pucamarca.

Como sugiere el caso de estudio, que explora uno de estos paisajes, los tambos no son meros marcadores de posición en una historia de la acumulación capitalista, la circulación global y la 


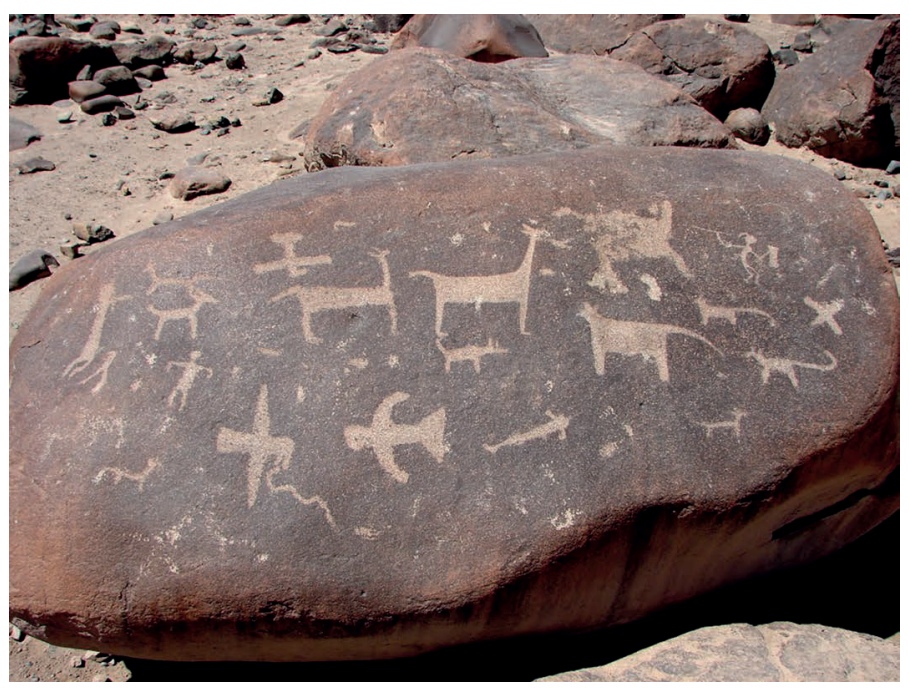

Figura 7. Arte rupestre prehispánico tardio (Miculla, Tacna) y un detalle del monumento a los caidos en la Guerra del Pacifico (Complejo Monumental Alto de la Alianza, Tacna).

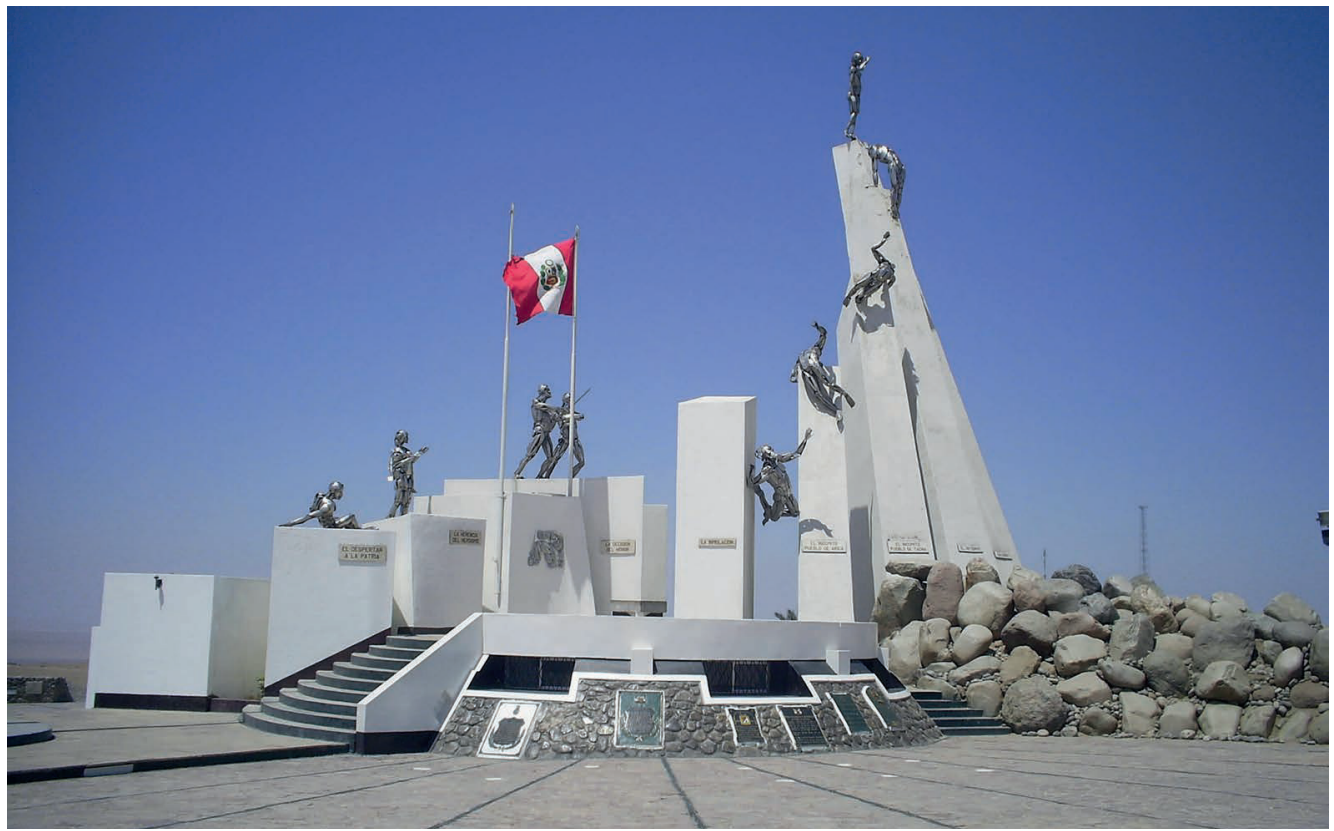

transformación colonial de una institución prehispánica (aunque estas sí son narrativas importantes). Sin desacelerar nuestro análisis y representando estos sitios también como lugares de la explotación de cuerpos que trabajan, las relaciones dinámicas locales entre humanos y animales, y una vida frecuentemente precaria en el camino, corremos el riesgo de replicar jerarquías de interés pasadas y presentes con poca consideración sobre sus injusticias y omisiones.

Algunos neomaterialistas han exigido un realismo más positivo (Bennett 2009, compara Washick et al. 2015) que aborde la insuficiencia de proyectos actuales de crítica y que explore nuevas posibilidades para la participación política basada en nuevos compromisos afectivos. Si bien este tipo de llamados audaces abordan una ausencia actual de visión utópica entre las humanidades, rara vez se acompañan de un marco claro para la praxis ( $c f$. Smith 2014 para una discusión reciente de las posibilidades y limitaciones de tales intervenciones intelectuales). Los espacios espectrales 
y ecologías coloniales encontrados en el caso de estudio sugieren una visión más complicada del mundo, una visión que coexiste inquietamente con las evocaciones de «reencantamiento" y "vitalidades». En estos contextos de violencia y explotación, el problema de la representación adecuada parece cernirse particularmente próximo. La combinación de algunas propuestas neomaterialistas (interrogar la partición de lo sensible, desarrollar nuevas jerarquías de interés, reabrir preguntas sobre la representación) con una atención arqueológica a lo material podría ayudar a enfrentar algunos escollos lingüísticos de la incapacidad para representar y compartir. En tanto se encuentren índices de transformaciones y violencias pasadas (frecuentemente poco espectaculares), las prácticas lentas hasta «forenses» de rastreo arqueológico permiten un modo modesto de testificar y presenciar las vidas de otra manera olvidadas ( $c f$. McGuire y Reckner 2003 Weizman 2014).

En este artículo he tratado de situar la practica arqueológica dentro de una discusión más amplia y corriente acerca de los «nuevos materialismos». El énfasis en una perspectiva desde la ecología política ha subrayado la complejidad de la «socionaturaleza» tan a menudo dividido en los dominios de lo social y lo natural, lo animado y lo inanimado. El caso de estudio — sobre la movilidad en la sierra tacneńa y ariqueña - exploró tanto la ecología política de la colonia y la poscolonia en los Andes, como los retos múltiples representados por sus historias de violencia y explotación contra lo humano y lo no humano. La exploración de dicha complejidad y los modos en que los neomaterialistas han tratado de entenderla, llevó la discusión hacía una serie de preguntas importantes y persistentes acerca las relaciones entre la práctica, la representación y la ética. Argumento que estas preguntas tienen implicaciones para la arqueología (dada su posición en la frontera entre lo cultural y lo natural), pero también que la arqueología (con sus prácticas «lentas» y su atención a lo material) puede ofrecer nuevas perspectivas a la discusión más amplia sobre una praxis neomaterialista.

\section{Agradecimientos}

Gracias a Francesca Fernandini, Luis Muro Ynonán, Rosemary Joyce y Guido Pezzarossi por las reuniones iniciales del SAA 2015 y del TAAS 2016 y las discusiones estimulantes que resultaron. También deseo expresar mis agradecimientos a George Chauca Iparraguirre, el director del Proyecto de Investigación Arqueológica Tambos de Palca, a Ariel Morrone y Carlos Osores Mendives, por su ayuda con la traducción del texto al espańol y al árbitro anónimo por sus comentarios.

\section{Nota}

1. «La creencia en la distinción ontológica entre representaciones y aquello que se pretende representar» (2007: 46, la traducción es nuestra).

\section{REFERENCIAS}

AHVD 31

1893- Intendencia de Tacna: Documentos sobre: Trabajadores de Caminos Públicos (planillas), Telégrafos del

1900 Estado, FF.CC. Arica a Tacna. In Fondo de la Intendencia de Tacna y Gobernación de Arica (1880-1929), Volume 31. Universidad de Tarapacá, Arica, Chile: Archivo Histórico Vicente Dagnino.

Alberti, B.

2007 Destabilizing meaning in anthropomorphic forms from Northwest Argentina, Journal of Iberian Archaeology 9 (10), 209-29.

Aldred, $\mathrm{O}$.

2014 Past Movements, Tomorrow's Anchors. On the Relational Entanglements between Archaeological Mobilities, en: J. Leary (ed.), Past Mobilities, 21-48, Ashgate Publishing, Burlington. 
Barad, K.

2007 Meeting the universe halfway: Quantum physics and the entanglement of matter and meaning, Duke University Press, Durham. https://doi.org/10.1215/9780822388128

Beall, C. M.

2014 Adaptation to high altitude: phenotypes and genotypes, Annual Review of Anthropology 43, $251-272$. https://doi.org/10.1146/annurev-anthro-102313-030000

Bennett, J.

2009 Vibrant matter: A political ecology of things, Duke University Press, Durham. https://doi. org/10.1215/9780822391623

Braun, B. y S. J. Whatmore

2010 The stuff of politics: An introduction, en: B. Braun y S. J. Whatmore (eds.), Political matter: Technoscience, democracy, and public life, ix-xl, University of Minnesota Press, Minneapolis.

\section{Cavagnaro, L.}

1988 Materiales para la historia de Tacna, tomo II: Dominación hispánica (s. XVI), Cooperativa San Pedro de Tacna, Tacna.

Chauca Iparraguirre, G. E.

2016 Proyecto de investigación arqueológica Tambos de Palca, valle alto del río Caplina, Tacna (temporada 2015), informe final entregado al Ministerio de Cultura, Lima.

Clarke, D. L.

1968 Analytical archaeology, Methuen, Londres.

Cobo, B.

1890 Historia del Nuevo mundo, tomo I, Impresiones de E. Rasco, Sevilla.

[1653]

Collins, H.M. y S. Yearley

1992 Epistemological chicken, en: A. Pickering (ed.), Science as practice and culture, 301-326, University of Chicago Press, Chicago.

Cook, N. D.

1981 Demographic collapse: Indian Peru, 1520-1620, Cambridge University Press, Cambridge.

Coole, D. y S. Frost (eds.)

2010 New materialisms: Ontology, agency, and politics, Duke University Press, Durham. https://doi. org/10.1215/9780822392996

\section{Corcoran-Tadd, N.}

2017 Tambos and the Andean longue durée: Landscapes of mobility in far southern Peru, tesis de doctorado, Departamento de Antropología, Harvard University, Cambridge.

Corcoran-Tadd, N. y G. Pezzarossi

2018 Between the south sea and the mountainous ridges: Biopolitical assemblages in the Spanish colonial Americas, Post-Medieval Archaeology 52 (1), 84-101. https://doi.org/10.1080/00794236.2018.1461326

Cowen, D.

2014 The deadly life of logistics, University of Minnesota Press, Minneapolis. https://doi.org/10.5749/ minnesota/9780816680870.001.0001

Cronon, W.

1991 Nature's metropolis: Chicago and the Great West, WW Norton \& Company, Nueva York.

\section{Cunningham, J. J. y S. MacEachern}

2016 Ethnoarchaeology as slow science, World Archaeology 48, 628-641. https://doi.org/10.1080/00438243.2 016.1260046

de Acosta, J.

1590 The natural \& moral history of the Indies [Traducido por E. Grimeston], C. R. Markham (ed.), Hakluyt

[1880] Society, Londres. 
de la Cadena, $M$.

2010 Indigenous cosmopolitics in the Andes: Conceptual reflections beyond «politics», Cultural Anthropology 25 (2), 334-370. https://doi.org/10.1111/j.1548-1360.2010.01061.x

De León, J.

2015 The land of open graves: Living and dying on the migrant trail, University of California Press, Berkeley.

Deetz, J.

1977 In small things forgotten: An archaeology of early american life, Doubleday, Nueva York.

deFrance, S. D.

2010 Paleopathology and health of native and introduced animals on Southern Peruvian and Bolivian Spanish Colonial sites, International Journal of Osteoarchaeology 20, 508-524. https://doi.org/10.1002/oa.1074

Descola, P.

2005 Par-del nature et culture, Gallimard, Paris.

Dupré, J.

2012 Processes of life: essays in the philosophy of biology, Oxford University Press, Oxford/Nueva York. https:// doi.org/10.1093/acprof:oso/9780199691982.001.0001

Earle, T. (ed.)

1993 Chiefdoms: power, economy, and ideology, Cambridge University Press, Cambridge.

Flannery, K.

1967 Culture history vs. culture process: a debate in American archaeology, Scientific American 217 (2), 119122. https://doi.org/10.1038/scientificamerican0867-119

Fowles, $S$.

2010 People without things, en: M. Bille, F. Hastrup y T. Flohr Soerensen, An Anthropology of Absence: Materializations of Transcendence and Loss, 23-41, Springer, Nueva York. https://doi.org/10.1007/978-14419-5529-6_2

Garcia, T.

2014 Form and object: A treatise on things, Edinburgh University Press.

Ginzburg, C.

1979 Clues, Theory and Society 7 (3), 273-288. https://doi.org/10.1007/BF00207323

Gotkowitz, L. (ed.)

2011 Histories of race and racism: The Andes and Mesoamerica from colonial times to the present, Duke University Press, Durham. https://doi.org/10.1215/9780822394334

Graeber, D.

2015 Radical alterity is just another way of saying «reality»: A reply to Eduardo Viveiros de Castro, HAU: Journal of Ethnographic Theory 5 (2), 1-41. https://doi.org/10.14318/hau5.2.003

Haraway, D. J.

2003 The companion species manifesto: Dogs, people, and significant otherness, Prickly Paradigm Press, Chicago.

Harvey, P. y H. Knox

2012 The enchantments of infrastructure, Mobilities 7 (4), 521-536. https://doi.org/10.1080/17450101.2012. 718935

Hodder, I.

2003 Archaeology beyond dialogue, University of Utah Press, Salt Lake City.

2012 Entangled: An archaeology of the relationships between humans and things, Wiley-Blackwell, Hoboken. https://doi.org/10.1002/9781118241912

Hodder, I. y S. Hutson

2003 Reading the past: current approaches to interpretation in archaeology, University Press, Cambridge. https:// doi.org/10.1017/CBO9780511814211 
Ingold, $\mathrm{T}$.

2000 The Perception of the Environment: essays on livelihood, dwelling and skill, Routledge, Nueva York.

2007 Materials against materiality, Archaeological dialogues 14 (1), 1-16. https://doi.org/10.1017/ S1380203807002127

Knappett, C.

2005 Thinking through material culture: An interdisciplinary perspective, University of Pennsylvania Press, Philadelphia. https://doi.org/10.9783/9780812202496

2011 An archaeology of interaction: network perspectives on material culture and society, Oxford University Press, Oxford. https://doi.org/10.1093/acprof:osobl/9780199215454.001.0001

LaMotta, V. M. y M. B. Schiffer

2001 Behavioral archaeology: toward a new synthesis, en: I. Hodder (ed.), Archaeological theory today, 14-64, Blackwell Publishers, Oxford.

Larson, B.

2004 Trials of nation making: liberalism, race, and ethnicity in the Andes, 1810-1910, Cambridge University Press, Cambridge. https://doi.org/10.1017/CBO9780511616396

Latour, B.

2004 Why has critique run out of steam? From matters of fact to matters of concern, Critical inquiry 30 (2), 225-248. https://doi.org/10.1086/421123

2007 Can we get our materialism back, please?, Isis 98 (1), 138-142. https://doi.org/10.1086/512837

Lau, G. F.

2010 The work of surfaces: object worlds and techniques of enhancement in the ancient Andes, Journal of Mtaterial Culure 15 (3), 259-286. https://doi.org/10.1177/1359183510373986

Law, J.

2004 After method: Mess in social science research, Routledge, Londres.

López Beltrán, C.

2016 La ruta de la plata de Potosí al Pacifico: caminos, comercio y caravanas en el os siglos XVI y XIX, Plural de Ediciones, La Paz.

Lucas, G.

2012 Understanding the archaeological record, Cambridge University Press, Cambridge.

Lumbreras, L. G.

1984 La arqueología como ciencia social, Casa de las Américas, La Habana.

Marshall, Y. y B. Alberti

2014 A matter of difference: Karen Barad, ontology and archaeological bodies, Cambridge Archaeological Journal 24 (1), 19-36. https://doi.org/10.1017/S0959774314000067

McGuire, R. H, y P. Reckner

2003 Building a working-class archaeology: The Colorado coal field war project, Industrial Archaeology Review 25 (2), 83-95. https://doi.org/10.1179/iar.2003.25.2.83

Mikhail, A.

2013 Unleashing the beast: Animals, energy, and the economy of labor in Ottoman Egypt, The American Historical Review 118 (2), 317-348. https://doi.org/10.1093/ahr/118.2.317

Monge, $\mathrm{C}$.

1937 High altitude disease, Archives of Internal Medicine 59 (1), 32-40. https://doi.org/10.1001/ archinte.1937.00170170038002

Mrozowski, S. A.

2006 Environments of history: Biological dimensions of historical archaeology, en: M. Hall y S. W. Silliman (eds.), Historical Archaeology, 23-41, Blackwell Publishing, Oxford.

Nativ, A.

2014 Anthropocentricity and the archaeological record: Towards a sociology of things, Norwegian Archaeological Review 47 (2), 180-195. https://doi.org/10.1080/00293652.2014.957235 
Olsen, B.

2003 Material culture after text: re-membering things, Norwegian Archeological Review 36 (2), 87-104. https:// doi.org/10.1080/00293650310000650

Overton, N. J. y Y. Hamilakis

2013 A manifesto for a social zooarchaeology. Swans and other beings in the Mesolithic, Archaeological Dialogues 20 (02), 111-136. https://doi.org/10.1017/S1380203813000159

Paulson, S., L. L. Gezon y M. Watts

2003 Locating the political in political ecology: An introduction, Human organization 62 (3), $205-217$. https://doi.org/10.17730/humo.62.3.e5xcjnd6y8v09n6b

Roberts, J. L.

2013 The power of patience, Harvard Magazine, 40-43.

Roth, J. P.

1999 The logistics of the Roman army at war (264 B.C.-A.D. 235), Brill, Leiden.

Sanhueza, C.

2011 Tráfico caravanero, arriería y trajines en Atacama colonial: síntesis y discusiones sobre un proceso de adaptación andina, en: A. Hubert, J. A. González y M. Pereira (eds.), Temporalidad, interacción y dinamismo cultural. La búsqueda del hombre. Homenaje al Dr. Lautaro Núñez Atencio, 289-321, Ediciones Universitarias, Universidad Católica del Norte, Antofagasta.

Sayer, A.

2000 Realism and social science, Sage, Nueva York. https://doi.org/10.4135/9781446218730

Schiffer, M. B.

1975 Archaeology as behavioral science, American Anthropologist 77 (4), 836-848. https://doi.org/10.1525/ aa.1975.77.4.02a00060

Shanks, M.

2004 Three rooms: archaeology and performance, Journal of Social Archaeology 4 (2), 147-180. https://doi. org/10.1177/1469605304041073

Smith, G.

2014 Intellectuals and (counter-) politics: Essays in historical realism, Berghahn Books, Nueva York.

Squier, E. G.

1877 Peru: Incidents of travel and exploration in the land of the Incas, Harper and Brothers, Nueva York.

Stengers, I.

2010 Including nonhumans in political theory: Opening Pandora's box?, en: B. Braun y S. J. Whatmore (eds.), Political matter: Technoscience, democracy, and public life, 3-34, University of Minnesota Press, Minneapolis.

Swyngedouw, E.

1999 Modernity and hybridity: nature, regeneracionismo, and the production of the Spanish waterscape, 18901930, Annals of the Association of American Geographers 89 (3), 443-465. https://doi.org/10.1111/00045608.00157

Tantaleán, $\mathrm{H}$.

2006 La arqueología marxista en el Perú: Génesis, despliegue y futuro, Arqueología y Sociedad (17), 19-32.

Tilley, C.

1991 Material culture and text: The art of ambiguity, Routledge, Londres.

1994 A phenomenology of landscape: places, paths, and monuments, Berg, Oxford.

Trigger, B. G.

2006 A History of archaeological thought, University Press, Cambridge. https://doi.org/10.1017/ CBO9780511813016 
Tripcevich, N.

2007 Quarries, caravans, and routes to complexity:Prehispanic obsidian in the south-central Andes, tesis de doctorado, Departamento de Antropología, University of California Santa Barbara.

Urton, G.

1988 La arquitectura pública como texto social: La historia de un muro de adobe en Pacariqtambo, Perú (1915-1985), Revista Andina 6 (1), 225-261.

Vaca de Castro, C.

1908 Ordenanzas de tambos. Distancias de unos a otros, modo de cargar los indios y obligaciones de las justicias

[1543] respectivas hechas en la ciudad del Cuzco en 31 de mayo de 1543, Revista Histórica, 427-491, La Opinión Nacional, Lima.

Vannini, P.

2015 Non-representational research methodologies: an introduction, en: P. Vannini (ed.), Non-representational methodologies: Re-envisioning research, 1-18, Routledge, Nueva York.

Viveiros de Castro, E.

1998 Cosmological deixis and Amerindian perspectivism, Journal of the Royal Anthropological Institute 4(3), 469-488. https://doi.org/10.2307/3034157

Washick, B., E. Wingrove, K. E. Ferguson y J. Bennett

2015 Politics that matter: Thinking about power and justice with the new materialists, Contemporary Political Theory 14 (1), 63-89. https://doi.org/10.1057/cpt.2014.19

Watts, C.

2013 Relational archaeologies: roots and routes, en: C. Watts (ed.), Relational archaeologies: humans, animals, things, 1-20, Routledge, Nueva York. https://doi.org/10.4324/9780203553138

Webmoor, T.

2007 What about 'one more turn after the social' in archaeological reasoning? Taking things seriously, World archaeology 39 (4), 563-578. https://doi.org/10.1080/00438240701679619

Webmoor, T. y C. L. Witmore

2008 Things are us! A commentary on human/things relations under the banner of a 'social' archaeology, Norwegian Archaeological Review 41 (1), 53-70. https://doi.org/10.1080/00293650701698423

Weismantel, $\mathrm{M}$.

2015 Seeing like an archaeologist: Viveiros de Castro at Chavín de Huantar, Journal of social archaeology 15 (2), 139-159. https://doi.org/10.1177/1469605315575425

Weizman, E.

2014 Introduction II: Matter against Memory, en: Forensic Architecture (eds.), Forensis. The Architecture of Public Truth, 361-380, Sternberg Press, Nueva York.

Wilkinson, $\mathrm{D}$.

2013 Politics, infrastructure and non-human subjects: The Inka occupation of the Amaybamba cloud forests, tesis de doctorado, Departamento de Antropología, Columbia University, Nueva York.

Williams, V. L., C. M. Santoro, Á. R. Guevara, J. Gordillo, D. Valenzuela y V. G. Standen

2009 Dominación Inca en los Valles Occidentales (Sur del Perú y Norte de Chile) y el Noroeste Argentino, Andes-Boletin del Centro de Estudios Precolombinos de la Universidad de Varsovia 7, 615-654.

Witmore, C.

2014 Archaeology and the new materialisms, Journal of contemporary archaeology 1 (2), 203-246. https://doi. org/10.1558/jca.v1i2.16661 